\title{
PENGENDALIAN KUALITAS PRODUK ELPIJI PSO (PUBLIC SERVICE OBLIGATION) DENGAN IMPLEMENTASI STATISTICAL PROCESS CONTROL
}

\author{
Donny Arif, Nikma Yucha \\ Program Studi Manajemen, Universitas Maarif Hasyim Latif Sidoarjo \\ e-mail:doni_arif@dosen.umaha.ac.id
}

\begin{abstract}
Domestic Gas Region V is division of the company PT Pertamina Persero which is engaged in providing domestic LPG, especially in the field distribution of PSO and non PSO LPG. Domestic Gas supply LPG through SPPBE (Station for Filling and Transporting LPG Bulk) to agents to direct consumers. Especially for the PSO LPG with a weight $3 \mathrm{~kg}$ is product of government subsidies with large scale production, it is necessary equalization of good quality for use by the middle to lower class society. In practices, many consumers feel that there are several differences between products one another, especially the difference in the weight of the filled tube and the diameter of the valve that is not the same, so it is difficult to install with the stove regulator and can cause gas leakage which in turn caused a fire. Implementation of statistical process control is carried out to measure the quality of LPG PSO so that it is expected to be able to maintain and improve the quality of PSO LPG products. Statistical process control is done because it exists differences in quality dispersion with the same product this needs to be done to meet the wants and needs of consumers and increase customer satisfaction. This research was conducted to measure the effectiveness/success in controlling and supervision of product quality by implementing statistical process control, the first is to measure the description of the quality of LPG products, the second is to measure how consumer satisfaction with LPG products. The results obtained show that statistical process control analysis illustrates that the performance criteria set by the holding company of PT Pertamina has been very good seen from the P-Chart control which produces the value "P" is in the lower limit of the lower control limit.
\end{abstract}

Keywords: Statistical process control, product quality, customer satisfaction

\section{PENDAHULUAN}

PT Pertamina (PERSERO) untuk melakukan pengalihan minyak tanah ke LPG bagi konsumen rumah tangga serta surat Wakil Presiden RI No.20WP/9/2006 Tanggal 1 September 2006 Perihal: Konversi Pemakaian Mitan ke LPG. Pada awalnya proses konversi direncanakan berjalan dari tahun 2007 dan selesai pada tahun 2010 untuk wilayah Jawa Timur, Bali, dan NTB. Dengan adanya konversi diproyeksikan akan terjadi penghematan APBN untuk keperluan subsidi secara nasional sebesar Rp17,01 Triliun per tahun. Selain dalam rangka penghematan anggaran subsidi negara, kebutuhan LPG di
Indonesia mempunyai peranan yang sangat penting dalam menunjang pembangunan. Selain sebagai penghasil devisa yang utama, juga untuk memenuhi kebutuhan energi dalam negeri. Dengan semakin, tingginya kebutuhan akan penggunaan elpiji nasional maka akan berdampak pula pada jumlah produksi dan supply yang akan disalurkan kepada konsumen. Oleh karena itu, diperlukan sistem pengendalian mutu kualitas produk untuk mengukur kesetaraan kualitas produk yang sama dalam setiap produksi. Statistical process control digunakan untuk pengendali mutu mengukur kualitas produk elpiji PSO dari mulai proses produksi hingga proses handling 
kepada agen resmi hingga akhirnya didistribusikan ke konsumen langsung. Dengan sistem penjualan titipan (konsinyasi) yaitu PT Pertamina selaku pemilik produk elpiji dengan SPPBE selaku rekan kerja yang bertugas melakukan pendistribusian dan pengisian ke tabung siap konsumsi maka diharapkan PT Pertamina akan lebih efisien dalam mengelola biaya yang akan dikeluarkan di setiap wilayah karena semua biaya pendirian fasilitas dan instalasi SPPBE sepenuhnya dilakukan oleh pihak swasta. PT Pertamina memberikan biaya balas jasa atas pengangkutan dan pengisian yang dilakukan oleh SPPBE. Dalam banyak teori sistem konsinyasi memiliki tingkat risiko yang sangat kecil terhadap kerugian atas barang dikarenakan semua risiko yang terjadi atas pendistribusian dan penjualan akan ditanggung oleh penjual atau rekan kerja yang menerima barang titipan (Arif et al., 2020). Produk elpiji sangat rentan losses (menyusut) dikarenakan sifat produk cair dan dapat menguap jika bercampur dengan udara, maka sistem pendistribusiannya harus dilakukan dengan metode kedap udara untuk menjaga liquid tetap dalam kapasitas yang sama ketika dari SPPBE hingga sampai kepada konsumen. Dengan alur yang demikian panjang sangat rentan pula kualitas produk menurun hingga sampai ke konsumen pengguna langsung, ditambah dengan perbedaan kadar density yang berubah setiap harinya. Hal ini yang mendorong kami untuk melakukan penelitian ini apakah implementasi statistical process control dalam melakukan pengendalian mutu kualitas produk dapat berjalan dengan baik sehingga produk elpiji PSO dapat diterima dan digunakan oleh konsumen secara baik dan meningkatkan kepuasan konsumen (Arif et al., 2019).

Penelitian ini digunakan juga untuk membentuk standardisasi pengukuran untuk kualitas produk pada produksi elpiji PSO sehingga diharapkan produk yang sudah terdistribusi ke konsumen memiliki tingkat kualitas produk yang terjaga dan aman digunakan (Nugroho et al., 2020). Penelitian ini juga dilakukan untuk mengukur efektivitas/keberhasilan pengendalian dan pengawasan kualitas produk dengan implementasi statistical process control, yang pertama adalah untuk mengukur gambaran kualitas produk elpiji, yang kedua untuk mengukur bagaimana kepuasan konsumen terhadap produk elpiji. Dalam implementasinya kualitas produk terdiri dari beberapa dimensi yang akan diukur tingkat kepuasan konsumen atas produk yang diberikan, setelah itu diketahui prioritas dimensi pelanggan yang perlu untuk ditingkatkan. Selanjutnya dirumuskan bagaimana teknis untuk meningkatkan kepuasan pelanggan atas dimensi kualitas produk.

\section{METODE}

Penelitian ini menggunakan metode implementasi statistical process control, karena metode tersebut cocok digunakan dalam pengukuran pengendalian dan pengawasan kualitas produk (Nugroho et al., 2021). Dalam awal pelaksanaannya nanti, peneliti akan mengumpulkan data dari pihak perusahaan DOMGAS Region V Surabaya PT Pertamina Persero dan beberapa perusahaan rekanan terkait dengan dimensi kualitas produk pada perusahaan tersebut, selain itu mengumpulkan informasi terkait dengan kepuasan konsumen elpiji kepada pelanggan di setiap rayon. Pengumpulan data atribut ini dilakukan, untuk mempermudah proses pengolahan data pada penelitian ini. Analisis data yang digunakan adalah dengan menggunakan beberapa alat bantu pada statistical process control menurut Heizer dan Render dalam bukunya Manaje- 
men Operasi (2015) sebagai berikut. (1) Mengumpulkan data produksi dan produk rusak (check sheet). Data yang diperoleh dari perusahaan terutama data produksi dan data produk rusak kemudian diolah menjadi tabel secara rapi dan terstruktur. Hal ini dilakukan agar memudahkan dalam memahami data tersebut hingga bisa dilakukan analisis lebih lanjut. (2) Membuat histogram agar mudah membaca atau menjelaskan data dengan cepat maka data tersebut perlu untuk disajikan dalam bentuk histogram yang berupa alat penyajian data secara visual dalam bentuk grafis balok yang memperlihatkan distribusi nilai yang diperoleh dalam bentuk angka. (3) Membuat peta kendali P (Pchart). Dalam menganalisis data penelitian ini, digunakan peta kendali $\mathrm{p}$ (peta kendali proporsi kerusakan) sebagai alat untuk pengendalian proses secara statistik. Penggunaan peta kendali $p$ ini adalah dikarenakan pengendalian kualitas yang dilakukan bersifat atribut, serta data yang diperoleh yang dijadikan sampel pengamatan tidak tetap dan produk yang mengalami kerusakan tersebut dapat diperbaiki lagi sehingga harus di tolak (reject). Adapun langkah-langkah dalam membuat peta kendali $\mathrm{p}$ sebagai berikut.

a. Menghitung persentase kerusakan

$$
P=n p / \mathrm{n}
$$

Keterangan:

np : Jumlah gagal dalam sub grup

$\mathrm{n}$ : Jumlah yang diperiksa dalam sub-grup: Hari ke-

b. Menghitung garis pusat/central line (CL). Garis pusat merupakan rata-rata kerusakan produk $(\mathrm{U})$

$\mathrm{CL}=\mathrm{p}=\sum \mathrm{np} / \sum \mathrm{n}$

Keterangan:

$\sum \mathrm{np}=$ Jumlah total yang rusak

$\sum \mathrm{n}=$ Jumlah Total yang diperiksa c. Menghitung batas kendali atas atau upper control limit (UCL). Rumus menghitung upper control limit:

$\mathrm{UCL}=\dot{\mathrm{p}}+3(\sqrt{ } \mathrm{p}(1-\mathrm{p}))$

Keterangan:

$\mathrm{P}=$ rata-rata kerusakan produk

$\mathrm{n}=$ total grup/sampel

d. Menghitung batas kendali bawah atau lower control limit.

Rumus menghitung lower control limit:

$\mathrm{UCL}=\dot{p}-3(\sqrt{ } \mathrm{p}(1-\mathrm{p}) / \mathrm{n})$

Keterangan:

$\dot{\mathrm{p}}=$ rata-rata kerusakan produk

$\mathrm{n}=$ jumlah produksi

Jika LCL $>0$ maka LCL dianggap $=0$. Apabila data yang diperoleh tidak seluruhnya berada dalam batas kendali yang ditetapkan maka hal ini berarti data yang diambil belum seragam. Hal tersebut menyatakan bahwa pengendalian kualitas yang dilakukan Domgas Region V Surabaya masih perlu perbaikan. Hal tersebut dapat dilihat pada grafik pchart, apabila ada titik yang berfluktuasi secara tidak beraturan yang menunjukkan bahwa proses produksi masih mengalami penyimpangan. Dengan peta kendali tersebut dapat diidentifikasi jenis-jenis kerusakan dari produk yang dihasilkan. Jenis-jenis kerusakan yang terjadi pada berbagai macam produk yang dihasilkan. (4) Mencari faktor penyebab yang paling dominan dengan diagram sebabakibat. Setelah diketahui masalah utama yang paling dominan dengan menggunakan histogram, maka dilakukan analisis faktor kerusakan produk dengan menggunakan fishbone diagram, sehingga dapat menganalisis faktor-faktor apa saja yang menjadi penyebab kerusakan produk. (5) Membuat rekomendasi/usulan perbaikan kualitas. Setelah diketahui penyebab terjadinya kerusakan produk maka dapat disusun sebuah rekomendasi 
atau usulan tindakan untuk melakukan perbaikan kualitas produk.

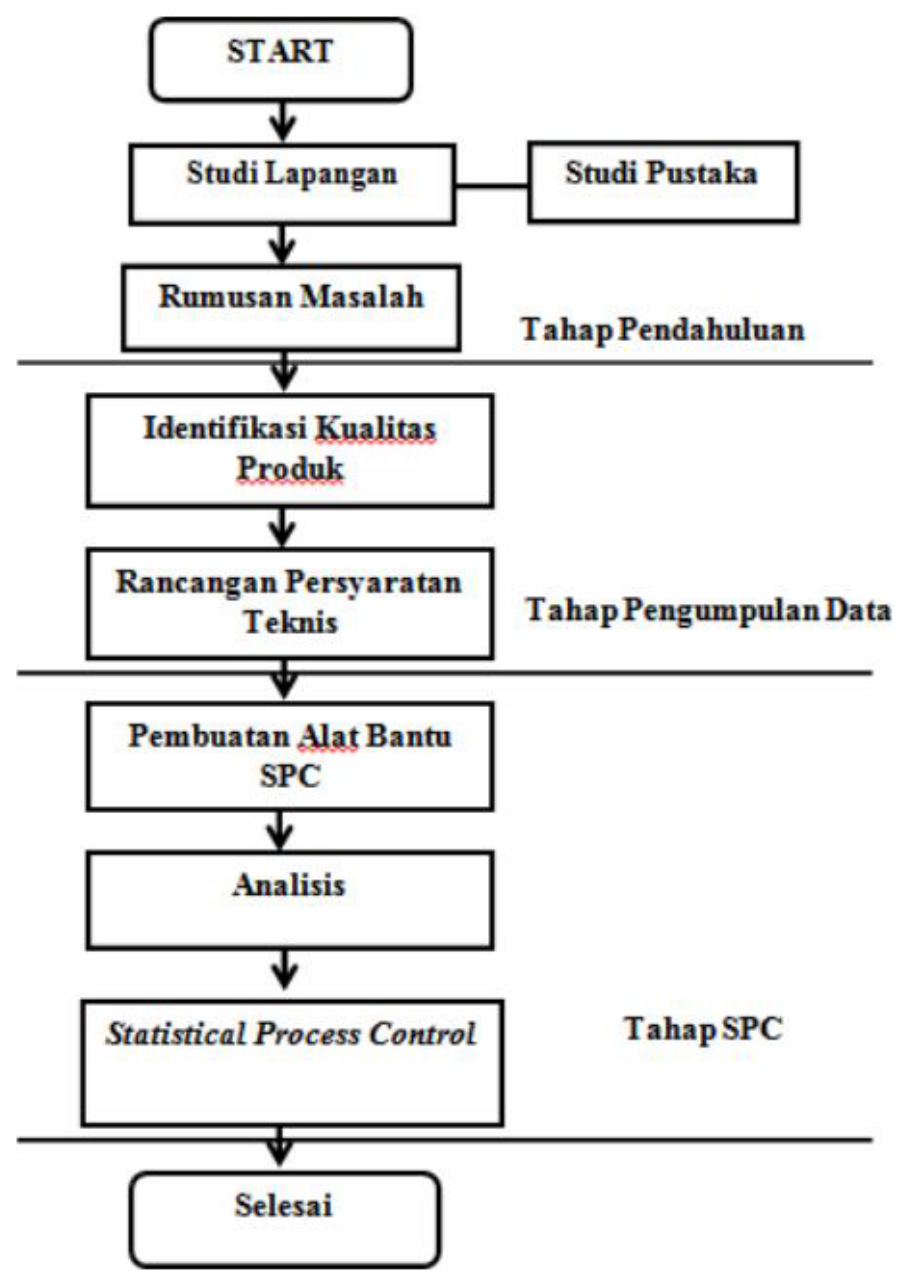

Gambar 1 Diagram Alir

Pengumpulan data dilakukan dengan melakukan wawancara dan mengambil sampling dari tiga SPPBE (Stasiun Pengisian dan Pengangkutan Bulk Elpiji) dan satu perusahaan re-tester yang khusus menangani perbaikan cat (repaint) dan retest berat tabung. Pengambilan sampling data diambil selama satu bulan proses produksi.

\section{HASIL DAN PEMBAHASAN}

Pembahasan penelitian terdiri dari analisis tingkat kerusakan tabung elpiji akibat dari proses produksi yang masih sangat kecil. Jumlah keru- sakan yang terjadi masih dapat dilakukan retest dan repaint untuk tabung agar dapat terus digunakan dan aman bagi konsumen. PT Pertamina terus melakukan upaya guna menekan kerusakan tabung yang dapat berakibat fatal bagi konsumen, untuk itu terus dilakukan upaya perbaikan secara terus menerus. Dari hasil penyajian rekapitulasi data selama satu bulan dapat digunakan untuk pengolahan data menggunakan peta kontrol kerusakan tabung elpiji subsidi. Metode yang digunakan adalah statistical process control (SPC) dengan menggunakan peta $P$ untuk mengukur keseimbangan pengendalian pengawasan kualitas tabung yang beredar di masyarakat. Menurut (Fourie et al., 2020) statistical process control adalah pendekatan statistik multi-variat yang digunakan untuk memproses kumpulan data yang dihasilkan selama proses manufaktur. Dari teori yang dikemukakan, peneliti membuat analisis untuk mendapatkan kesimpulan apakah selama proses produksi pengisian elpiji di SPPBE terjadi banyak kerusakan atau tidak sehingga pengguna elpiji bersubsidi yaitu masyarakat merasa aman. Tabel di bawah ini menunjukkan perhitungan persentase kerusakan tabung elpiji selama satu bulan produksi.

Pengolahan data dilakukan dengan perhitungan proporsi reject, perhitungan central line (CL), perhitungan upper control limit UCL), dan lower control limit (LCL). Analisis yang dilakukan adalah menggunakan diagram sebab akibat. Penelitian yang dilakukan (Kaban, 2016) juga memberikan penjelasan bahwa perhitungan reject produksi karena kerusakan dengan menggunakan metode statistical process control dapat dijadikan acuan dalam pengendalian kualitas. Contoh perhitungan UCL hari pertama: $\dot{p}=$ nilai rata-rata persentase rusak $=0,1666$

$$
\begin{aligned}
\mathrm{UCL} & =\dot{\mathrm{p}}+3 \sqrt{\mathrm{p}(1-\mathrm{p}) / n} \\
& =0,1666+3 \sqrt{ } 0,1666(1-0,1666) / 30315 \mathrm{UCL} \\
& =0,006796
\end{aligned}
$$




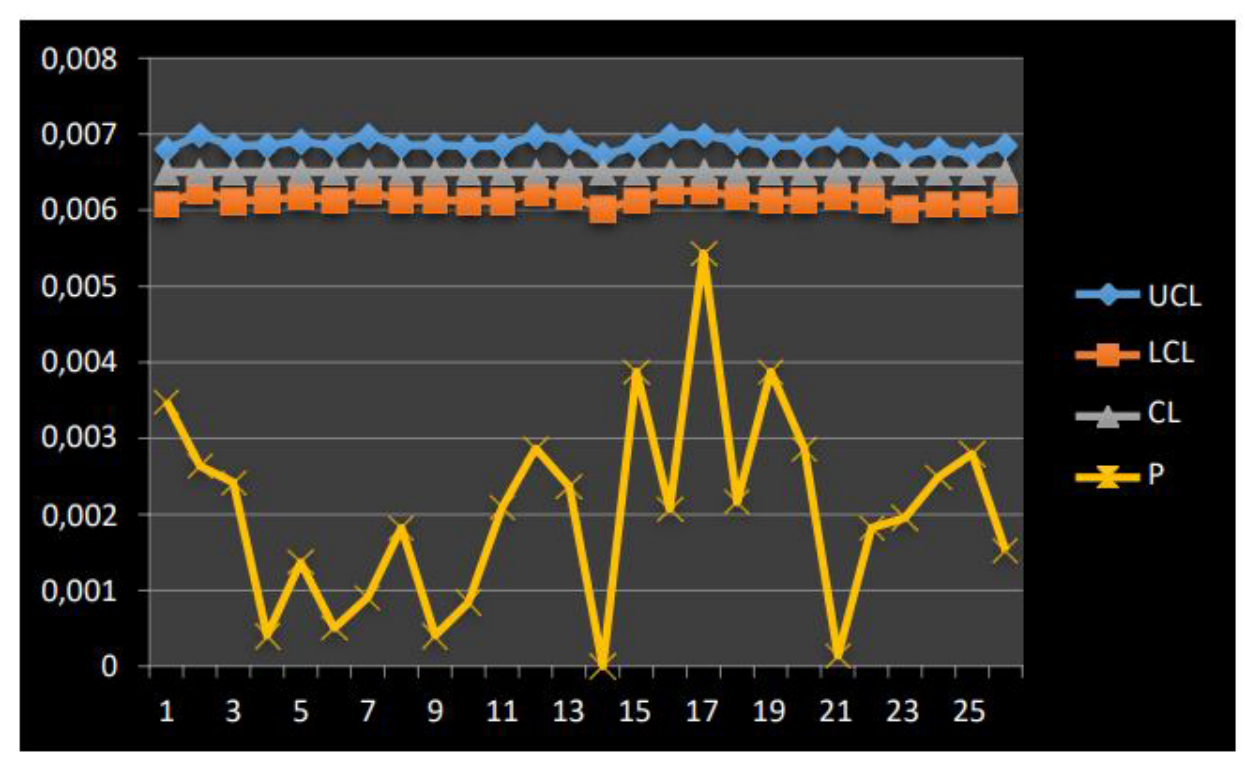

Gambar 2 Peta Kendali P-Chart

Berikut ini dapat dilihat peta kendali "P" UCL, LCL, dan CL dari produksi selama satu bulan untuk asumsi kerusakan dan perbaikan tabung elpiji $3 \mathrm{~kg}$. Peta Kendali digunakan untuk mengidentifikasi proses secara statistika sehingga dapat diketahui produk yang out of control (Polomarto, 2013).

Dari gambar peta kendali P-Chart tersebut semua titik berada di bawah garis kontrol sehingga kerusakan yang diakibatkan proses produksi dan penggunaan tabung elpiji di masyarakat dapat diminimalisasi dengan sangat baik oleh PT Pertamina, namun kerusakan yang terjadi masih perlu harus ditekan dengan penambahan alokasi retest dan repaint oleh PT Pertamina kepada perusahaan rekanan guna pengendalian kualitas tabung yang semakin baik dan aman digunakan oleh masyarakat. Seiring dengan penelitian (Fadly, 2015) yang mengusulkan perbaikan mekanisme perbaikan kualitas pengisian tabung elpiji dengan metode six sigma, dikarenakan masih ada ribuan tabung yang mengalami kerusakan dan ratusan tabung rusak yang masih belum tercover untuk diperbaiki oleh re-tester maka sistem pengendalian kualitas tabung masih harus ditingkatkan.

(Coccia, 2017) menyatakan bahwa diagram fishbone digunakan untuk analisis teknologi yang disebut juga dengan diagram ishikawa atau sebab-akibat adalah teknik grafis untuk menunjukkan beberapa penyebab dari suatu peristiwa dan fenomena tertentu. Gambar 3 diagram fishbone tentang keberhasilan dalam pengendalian dan pengawasan kualitas produk tabung elpiji PSO. Penjelasan dari diagram fishbone/sebabakibat terjadinya kerusakan sebagai berikut. (1) Lingkungan, yaitu lingkungan dapat memengaruhi daya tahan tabung gas serta atributnya, diketahui tabung gas elpiji diangkut menggunakan truck bak terbuka dan beberapa tabung masih berada di luar filling hall tanpa atap, sehingga langsung terkena sinar matahari, menyebabkan lebih cepat untuk cat cepat mengelupas dan berkarat. Di tempat lain ditemukan SPPBE lingkungan pesisir dekat dengan air laut menyebabkan tabung gas elpiji lebih mudah untuk berkarat karena panas yang lebih terik. Dan yang terakhir adalah air tanah yang terkon- 


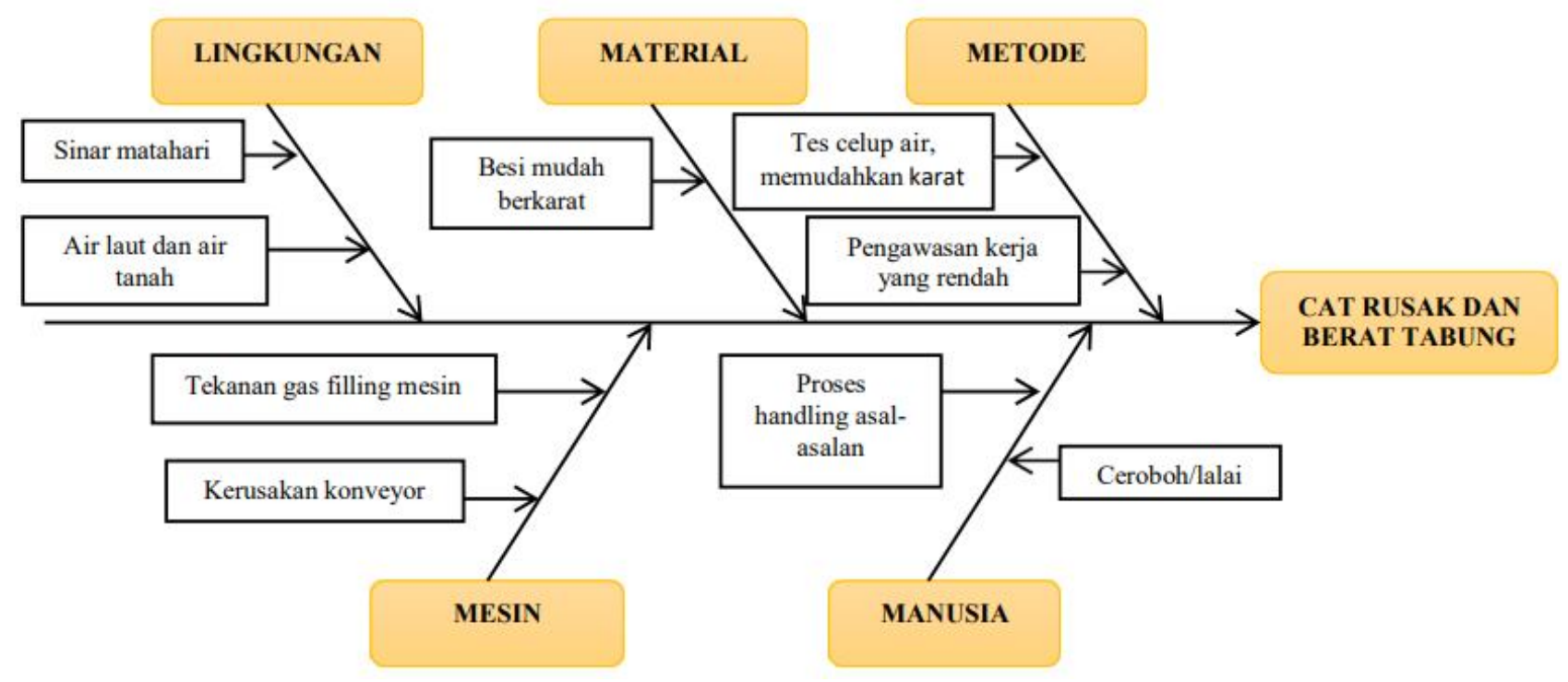

Gambar 3 Diagram Fishbone/Sebab-Akibat

taminasi dengan limbah industri membuat tabung gas lebih cepat menguning dan berkarat, karena air tanah masih digunakan misalnya untuk bak kontrol kebocoran tabung gas pada proses produksi. (2) Material, yaitu material yang digunakan menggunakan plat besi ketebalan $2,3 \mathrm{~mm}$, material ini mudah untuk berkarat jika tidak digunakan sesuai dengan SOP. Misalnya, tabung harus berada tempat yang tidak terkena sinar matahari langsung, ditempatkan di area terbuka dengan atap sebagai penghalang sinar matahari langsung. (3) Metode, yaitu metode yang digunakan adalah proses produksi mengharuskan SPPBE melakukan sampling tabung ke dalam bak celup air untuk tes kebocoran hal ini juga menyebabkan tabung gas lebih mudah untuk berkarat jika air yang digunakan tidak dengan kualitas baik. Yang kedua, pengawasan yang kurang terhadap semua proses pengisian menyebabkan terjadinya kerusakan dan kebocoran gas. (4) Mesin, ratarata SPPBE menggunakan mesin semi otomatis dengan tekanan yang tinggi, akan tetapi kerusakan tidak selalu disebabkan karena mesin melainkan kondisi tabung yang memang sudah aus, misalnya valve yang sudah terlalu lama bisa menimbulkan kebocoran karena tekanan mesin. Dan yang kedua adalah kerusakan konveyor menyebabkan perputaran elpiji pada saat pengisian hingga handling baik keluar dan masuk truk dilakukan secara manual, ini dapat menyebabkan banyak sekali benturan yang diakibatkan proses handling secara manual. (5) Manusia, kelalaian pekerja yang paling sering ditemukan pada proses produksi pengisian tabung elpiji, masih ada beberapa pekerja yang melakukan proses handling dengan asal-asalan, melempar tabung, menggelindingkan tabung yang dapat menyebabkan kerusakan tabung gas lebih cepat. Dari hasil analisis statistical process control yang tampak baik dapat disimpulkan bahwa kriteria dimensi kualitas dapat terpenuhi sesuai yang teori yang disampaikan Kenyon \& Sen (2011) terdapat delapan dimensi kualitas untuk mengetahui kepuasan konsumen dari penggunaan sebuah produk. Hasil analisis SPC menggambarkan bahwa kriteria kinerja yang dilakukan perusahaan induk PT Pertamina sudah sangat baik dilihat dari peta kendali P-Chart yang menghasilkan 
nilai "P" berada di batas bawah lower control limit, PT Pertamina menggunakan jasa perbaikan tabung baik pengecatan ulang dan retest berat tabung secara terus-menerus di seluruh wilayah rayon. Selanjutnya, dimensi fitur atau ciri-ciri tambahan yang melengkapi manfaat dasar produk (Hartnett et al., 1988) dilakukan seperti penambahan pengaman valve dan identitas masa penggunaan tabung gas seperti identitas tahun pembuatan dan kode berapa kali telah diperbaiki hingga tidak diperkenankan untuk digunakan kembali.

\section{KESIMPULAN DAN SARAN}

Kesimpulan dan hasil penelitian ini adalah sebagai berikut.

1. Lingkungan dapat memengaruhi daya tahan tabung gas serta atributnya. SPPBE lingkungan pesisir dekat air laut menyebabkan tabung gas elpiji lebih mudah berkarat.

2. Material yang digunakan pada elpiji mudah berkarat jika tidak digunakan sesuai SOP.

3. Metode yang digunakan adalah proses produksi mengharuskan SPPBE melakukan sampling tabung ke dalam bak celup air untuk tes kebocoran hal ini juga menyebabkan tabung gas lebih mudah untuk berkarat jika air yang digunakan tidak dengan kualitas baik.

4. Kelalaian pekerja yang paling sering ditemukan pada proses produksi pengisian tabung elpiji, masih ada beberapa pekerja yang melakukan proses handling dengan asal-asalan, melempar tabung, menggelindingkan tabung yang dapat menyebabkan kerusakan tabung gas lebih cepat.

5. Hasil analisis statistical process control menggambarkan bahwa kriteria kinerja yang dilakukan perusahaan induk PT Pertamina sudah sangat baik.

\section{DAFTAR RUJUKAN}

Coccia, M. (2017). The Fishbone Diagram to Identify, Systematize, and Analyze the Sources of General Purpose Technologies, 4, 291-303. https://doi.org/10.1453/ jsas.v4i4.1518.

Arif, D., Yucha, N., Setiawan, S., Oktarina, D., Martah, V., \& Muttaqiin, N. (2020). Applications of Goods Mutation Control Form in Accounting Information System: A Case Study in Sumber Indah Perkasa Manufacturing, Indonesia. The Journal of Asian Finance, Economics and Business, 7(8), 419-424.

Arif, D., Yucha, N., Rosidi, E, (2019). Sistem Pengendalian Intern Pembelian Spare Part Forklif oleb PT Grogol Sarana Transjaya. 2(1), 21-30.

Nugroho, M., Arif, D., \& Halik, A. (2021). The effect of loan-loss provision, non-performing loans and third-party fund on capital adequacy ratio. Accounting, 7(10), 943950. https://doi.org/10.5267/j.ac.2021.1. 013.

Nugroho, M., Halik, A., \& Arif, D. (2020). Effect of CAMELS Ratio on Indonesia Banking Share Prices. 7(11), 101-106. https:// doi.org/10.13106/jafeb.2020.vol7.no11. 101.

Fadly Dzil Faza Fakhrudin \& Ambar Harsono, D. N. (2015). Usulan Perbaikan Peningkatan Kualitas Proses Pengisian Tabung Gas Elpiji $3 \mathrm{~kg}$ Menggunakan Metode Six Sigma. Jurnal Online Institut Teknologi Nasional, 3(2), 399-409.

Fourie, E., Aleixandre-Tudo, J. L., Mihnea, M., \& du Toit, W. (2020). Partial least squares calibrations and batch statistical process control to monitor phenolic extraction in red wine fermentations under different 
maceration conditions. Food Control, 115, 107303. https://doi.org/https://doi.org/ 10.1016/j.foodcont.2020.107303.

Hartnett, J., Schechter, S., Kropp, D., \& Garvin, D. (1988). Managing Quality: The Strategic and Competitive Edge. The Academy of Management Review, 13, 656. https:// doi.org/10.2307/258383.

Kaban, R. (2016). Pengendalian Kualitas Kemasan Plastik Pouch Menggunakan Statistical process control (SPC) di PT Incasi Raya
Padang. Jurnal Optimasi Sistem Industri, 13(1), 518. https://doi.org/10.25077/josi. v13.n1.p518-547.2014.

Kenyon, G. \& Sen, K. (2011). Customer's Perceptions and the Dimensions of Quality. https://doi.org/10.13140/2.1.4738.4326.

Polomarto, D. S. (2013). Implementasi Pengendalian Kualitas pada Proses Produksi Karton Kotak Makan Duplex 22x22x8Cm UD Wing on Surabaya, 2(1), 1-19. 